\title{
AVALIAÇÃO PRELIMINAR DO USO DE TORTA DE MAMONA NO MANEJO DA HÉRNIA DAS CRUCÍFERAS EM COUVE-FLOR
}

\author{
Carlos Antônio dos Santos ${ }^{1}$, Caio Soares Diniz ${ }^{1}$, Jéssica de Oliveira Lima ${ }^{1}$, Lucas da Silva de Souza Oliveira ${ }^{1}$, \\ Nelson Moura Brasil do Amaral Sobrinho ${ }^{2}$, Margarida Goréte Ferreira do Carmo ${ }^{1}$ \\ ${ }^{1}$ Universidade Federal Rural do Rio de Janeiro - UFRRJ, Departamento de Fitotecnia, RJ, ${ }^{2}$ Departamento de Solos. E- \\ mail: carlosantoniokds@gmail.com
}

\section{RESUMO}

A produção de couve-flor e demais brássicas vem sendo impactada, em nível mundial, devido à ocorrência da doença hérnia das crucíferas, causada por Plasmodiophora brassicae (Wor.). Diante disso, torna-se necessário a busca por estratégias de manejo que possam contribuir na redução das perdas causadas pela doença. Este trabalho objetivou, de forma preliminar, avaliar os efeitos de doses de torta de mamona (TM) na severidade da hérnia das crucíferas e no crescimento de plantas de couve-flor. Foram realizados dois ensaios em casa de vegetação, em tubetes e em vasos, respectivamente. No primeiro, avaliou-se os efeitos de doses de $\operatorname{TM}\left(0,10,20\right.$ e $\left.40 \mathrm{Mg} \mathrm{ha}^{-1}\right)$ na incidência da doença e na massa seca da parte aérea (MSPA). No segundo, avaliou-se o efeito das doses de $\operatorname{TM}\left(0,10,20,30\right.$ e $\left.40 \mathrm{Mg} \mathrm{ha}^{-1}\right)$ na severidade da doença, atributos das raízes e acúmulo de biomassa nas plantas. Observou-se redução da incidência e aumento da MSPA com o aumento das doses de TM $(p<0,05)$. Observou-se ainda, decréscimos na severidade da doença e incrementos no crescimento das raízes sadias em função das doses $(p<0,05)$. Adicionalmente, observaram-se efeitos positivos das doses de TM na altura das plantas, número e massa seca das folhas, e massa seca de caule e raízes. Conclui-se que a utilização de TM é uma alternativa promissora no manejo da doença e que novos estudos devem ser realizados em condições de campo e com ciclo mais longo.

Palavras-chave: Brassica oleracea var. botrytis; Plasmodiophora brassicae; adubação orgânica; controle; Ricinus communis.

\section{PRELIMINARY EVALUATION OF THE USE OF CASTOR BEAN CAKE IN THE MANAGEMENT OF CLUBROOT IN CAULIFLOWER}

\begin{abstract}
The production of cauliflower and other brassicas has been impacted worldwide due to the occurrence of the disease clubroot, caused by Plasmodiophora brassicae (Wor.). Therefore, it is necessary to search for disease management strategies that may contribute to reducing the losses caused. The objective of this work was to evaluate the effects of doses of castor bean cake (CK) on the severity of the disease and on the growth of cauliflower plants. Two experiments were carried out in a greenhouse where, in tubes and pots, respectively. In the first one, the effects of $C K$ doses $\left(0,10,20\right.$ and $\left.40 \mathrm{Mg} \mathrm{ha}^{-1}\right)$ on the disease incidence and dry mass of the aerial part of plants (DMAP) were evaluated. In the second, the effects of the doses of CK $\left(0,10,20,30\right.$ and $\left.40 \mathrm{Mg} \mathrm{ha}^{-1}\right)$ on disease severity, root attributes and biomass accumulation in plants were evaluated. Significant differences were observed in incidence, which decreased, and DMAP, that increased, as a function of doses. There were decreases in the severity of the disease and increases in the growth of healthy roots. In addition, positive effects on plant height, number of leaves and dry mass of leaves, stems and roots were observed. It is concluded that the use of castor bean cake was promising and further studies should be performed under field conditions and with longer cycle times.
\end{abstract}

Keywords: Brassica oleracea var. botrytis; Plasmodiophora brassicae; organic fertilization; control; Ricinus communis. 


\section{INTRODUÇÃO}

A hérnia das crucíferas, causada pelo protozoário Plasmodiophora brassicae Woronin, é um dos grandes desafios a serem superados nas principais regiões produtoras de couve-flor (Brassica oleracea var. botrytis) e demais espécies de Brassica no Brasil e no mundo (DIXON, 2009a,b; PENALBER, 2009; GOSSEN et al., 2014; BHERING et al., 2017; SANTOS et al., 2017). O patógeno, um parasita obrigatório e habitante do solo, infecta as raízes de suas hospedeiras causando galhas (hérnias) que reduzem o sistema radicular ativo e, consequentemente, a absorção de água e nutrientes, resultando em subdesenvolvimento das plantas (PENALBER, 2009; GOSSEN et al., 2014).

As estratégias de redução dos danos causados pela doença são extremamente limitadas após a dispersão do patógeno (GOSSEN et al., 2014). O seu manejo deve ser feito por meio de práticas preventivas, como exemplo a correção da acidez do solo (SANTOS et al., 2017), rotação de culturas e uso de cultivares resistentes, quando disponíveis (DONALD; PORTER, 2009). Não existe uma medida pontual de controle que seja eficaz quando aplicada isoladamente (DONALD; PORTER, 2009), o que justifica a busca por novas estratégias a serem utilizadas na redução dos danos causados pela doença.

Diversos trabalhos apontam efeito positivo de torta de mamona (TM) (Ricinus communis L.) como fertilizante orgânico (SILVA et al., 2012; SILVA et al., 2016; GOMES et al., 2017, MELLO et al., 2018), enquanto outros indicam efeitos positivos no controle de nematoides como Meloidogyne javanica (SEVERINO et al., 2012; FERREIRA, 2012). Não existem relatos, porém, sobre a utilização de TM no manejo da hérnia das crucíferas e em plantas de couve-flor.

Diante do exposto, o presente trabalho objetivou, de forma preliminar, avaliar os efeitos de diferentes doses de TM na severidade da hérnia das crucíferas e no crescimento de plantas de couve-flor.

\section{MATERIAL E MÉTODOS}

Foram realizados dois ensaios em casa de vegetação climatizada com temperatura ajustada para $28{ }^{\circ} \mathrm{C}$ e umidade relativa do ar interna para $70 \%$. No primeiro, realizado de maio a junho de 2016, avaliou-se em tubetes, os efeitos das doses $0,10,20$ e $40 \mathrm{Mg} \mathrm{ha}^{-1}$ de torta de mamona (TM)
(R. communis) na incidência da doença e na massa seca da parte aérea de couve-flor. No segundo, realizado de junho a agosto de 2017, avaliou-se em vasos, os efeitos das doses 0,10 , 20, 30 e $40 \mathrm{Mg} \mathrm{ha}^{-1}$ na severidade da doença, atributos das raízes e acúmulo de biomassa nas plantas.

No primeiro ensaio utilizou-se solo coletado em área de lavoura comercial de couveflor localizada em Nova Friburgo-RJ, naturalmente contaminado pelo patógeno $\left(4,8 \times 10^{7}\right.$ esporos $\left.\mathrm{g} \mathrm{solo}^{-1}\right)$ e homogeneizado em betoneira. A determinação da concentração de esporos de resistência do patógeno foi feita usando metodologia descrita em Bhering et al. (2017).

O solo utilizado foi classificado como CAMBISSOLO HÁPLICO (SANTOS et al., 2013), e apresentava os seguintes atributos químicos: $\mathrm{pH}_{\text {(água 1:2,5) }}=4,90 ; \mathrm{Ca}=4,80 \mathrm{cmol}_{\mathrm{c}} \mathrm{dm}^{-3} ; \mathrm{Mg}=1,40$ $\mathrm{cmol}_{\mathrm{c}} \mathrm{dm}^{-3} ; \mathrm{Na}=0,038 \mathrm{cmol}_{\mathrm{c}} \mathrm{dm}^{-3} ; \mathrm{Al}=0,50 \mathrm{cmol}_{\mathrm{c}}$ $\mathrm{dm}^{-3} ; \mathrm{H}+\mathrm{Al}=12,80 \mathrm{cmol}_{\mathrm{c}} \mathrm{dm}^{-3} ; \mathrm{CTC}=19,6 \mathrm{cmol}_{\mathrm{c}}$ $\mathrm{dm}^{-3} ; \mathrm{K}=236,0 \mathrm{mg} \mathrm{dm}^{-3} ; \mathrm{P}=56,0 \mathrm{mg} \mathrm{dm}^{-3} ; \mathrm{C}=$ $1,64 \%$, M.O. $=2,83 \%$ e V $=25 \%$.

Primeiramente, mudas de couve-flor da cv. Bola de Neve, com 30 dias de idade, foram transplantadas para tubetes de $110 \mathrm{~cm}^{3}$ preenchidos com uma mistura homogeneizada de solo e TM nas respectivas doses. A quantidade de TM aplicada nos tubetes foi calculada com base no volume de solo utilizado e considerandose a área de 1,0 ha, profundidade de $0,20 \mathrm{~m}$ e densidade do solo igual a $1,0 \mathrm{Mg} \mathrm{m}^{-3}$. Utilizou-se torta de mamona comercial ( $\mathrm{N}$ total $=5 \%$, Carbono orgânico $=35 \%, \mathrm{pH}=6,5)$. No ato do transplantio, lavaram-se as raízes para remoção do substrato aderido de modo a facilitar o contato destas com o solo contaminado.

Adotou-se o delineamento de blocos ao acaso com quatro repetições, e cinco tubetes por parcela.

Após 30 dias do transplantio, coletaramse as plantas e removeram-se as suas raízes. Estas foram lavadas e analisadas quanto à presença de sintomas da hérnia e determinada a incidência da doença. Adicionalmente, determinou-se a massa seca de parte aérea (MSPA), após secagem em estufa a $70{ }^{\circ} \mathrm{C}$ por 96 horas.

No segundo ensaio, utilizaram-se vasos com capacidade para $3,6 \mathrm{~L}$, preenchidos com solo coletado na camada superficial $(0-20 \mathrm{~cm})$ de PLANOSSSOLO HÁPLICO (SANTOS et al., 2013), com os seguintes atributos químicos: $\mathrm{pH}_{\text {(água 1:2,5) }}=$ 
4,90; $\mathrm{Ca}=2,00 \mathrm{cmol}_{\mathrm{c}} \mathrm{dm}^{-3} ; \mathrm{Mg}=1,00 \mathrm{cmol}_{\mathrm{c}} \mathrm{dm}^{-3}$; $\mathrm{Na}=0,08 \mathrm{cmol}_{\mathrm{c}} \mathrm{dm}^{-3} ; \mathrm{Al}=0,10 \mathrm{cmol}_{\mathrm{c}} \mathrm{dm}^{-3} ; \mathrm{H}+\mathrm{Al}=$ $4,1 \mathrm{cmol}_{\mathrm{c}} \mathrm{dm}^{-3} ; \mathrm{CTC}=7,30 \mathrm{cmol}_{\mathrm{c}} \mathrm{dm}^{-3} ; \mathrm{K}=57,0$ $\mathrm{mg} \mathrm{dm}{ }^{-3} ; \mathrm{P}=15,0 \mathrm{mg} \mathrm{dm}^{-3}$ e $\mathrm{V}=37 \%$. O solo utilizado foi proveniente do Setor de Horticultura da UFRRJ, localizado em Seropédica-RJ, em área sem histórico de plantio de brássicas ou de ocorrência da hérnia das crucíferas.

Utilizou-se torta de mamona comercial com as mesmas características descritas anteriormente e aplicada de forma parcelada, no transplantio (50\%), incorporando-a ao solo com uso de betoneira, e o restante (50\%) em cobertura aos 30 dias após o transplantio (DAT). A quantidade aplicada nos vasos foi calculada conforme descrito no ensaio anterior.

Transplantaram-se duas mudas de couveflor por vaso, cultivar Sharon, com 30 dias de idade, seguido de desbaste aos 7 DAT deixandose uma muda por vaso, totalizando-se 20 plantas úteis. A inoculação foi feita logo após transplantio por meio da rega de $50 \mathrm{~mL}$ vaso ${ }^{-1}$ de suspensão contendo $6,0 \times 10^{6}$ esporos $\mathrm{mL}^{-1}$ de $P$. brassicae. $\mathrm{O}$ inóculo foi obtido a partir da trituração de 1 grama de galha congelada, filtragem em 4 camadas de tecido musseline e avolumando-se o filtrado para $50 \mathrm{~mL}$ utilizando-se água destilada autoclavada. A contagem de esporos foi feita sob microscópio ótico com utilização de câmara de Neubauer. As galhas utilizadas no preparo foram provenientes de raízes de couve-flor coletadas em lavoura comercial localizada em Nova Friburgo-RJ.

$\mathrm{Na}$ adubação de plantio, foram aplicados superfosfato simples (equivalente a $90 \mathrm{~kg} \mathrm{ha}^{-1} \mathrm{de}$ $\left.\mathrm{P}_{2} \mathrm{O}_{5}\right)$ e cloreto de potássio $\left(30 \mathrm{~kg} \mathrm{ha}^{-1}\right.$ de $\left.\mathrm{K}_{2} \mathrm{O}\right)$. A adubação de cobertura foi realizada aos 30 DAT com aplicação de cloreto de potássio $\left(30 \mathrm{~kg} \mathrm{ha}^{-1}\right.$ de $\mathrm{K}_{2} \mathrm{O}$ ), além da aplicação de TM, conforme anteriormente mencionado. Irrigou-se por aspersão, conforme as necessidades hídricas das plantas.

Adotou-se delineamento em blocos ao acaso com 5 tratamentos e quatro repetições.

As plantas foram avaliadas aos 60 DAT, no início do florescimento. Nesta ocasião, coletaram-se as plantas e separaram-se as raízes. Estas foram lavadas e, em seguida, avaliadas individualmente quanto à severidade da doença com base em escala de Santos et al. (2017) composta por sete níveis de severidade: $0 \%$; $8 \%$; $20 \%$; $42 \%$; $68 \%$; $87 \%$ e $95 \%$ de raízes com hérnias. Posteriormente, as raízes foram segmentadas em fração sadia (isenta de sintomas) e doente (com presença de galhas). Determinou-se o volume das frações sadias (VRS) e das hérnias (VRH) medindo-se o deslocamento de água em proveta graduada (BHERING et al., 2017). Determinou-se também a massa fresca das frações sadias (MFRS) e com hérnias (MFRH) através de pesagem em balança de precisão.

$\mathrm{Na}$ parte aérea foram mensurados o número de folhas (NF), altura da planta e a massa fresca das folhas e do caule. Posteriormente, as amostras de folhas, caules e de raízes (total) foram secas em estufa por $70{ }^{\circ} \mathrm{C}$ até peso constante para obtenção dos valores de massa seca das folhas (MSF), de caule (MSC) e de raiz (MSRT).

Os dados obtidos, em ambos os ensaios, foram submetidos a analise de variância (ANOVA) e, em função da significância para o fator dose, foi realizada análise de regressão considerandose modelos lineares ou quadráticos. Utilizou-se o software estatístico SISVAR (FERREIRA, 2011) e significância $p \leq 0,05$.

\section{RESULTADOS E DISCUSSÃO}

No primeiro ensaio, observou-se efeito linear $(p \leq 0,05)$ de dose na incidência da doença, e efeito quadrático no acúmulo de massa seca da parte aérea. Houve decréscimo $(r=-1,16)$ na incidência da doença em função do aumento das doses de TM, de $83,3 \%$ na dose de $0,0 \mathrm{Mg} \mathrm{ha}^{-1}$ a $33,3 \%$ na dose de $40 \mathrm{Mg} \mathrm{ha}^{-1}$ (Figura 1A). Em resposta aos acréscimos de nutrientes e, possivelmente, pela redução da incidência da hérnia, houve incrementos no acúmulo de massa seca da parte aérea como aumento das doses de TM até a dose de $40 \mathrm{Mg}_{\text {ha }}{ }^{-1}$. $O$ acréscimo em massa seca com a aplicação de TM foi da ordem de $160 \%$ no tratamento com $40 \mathrm{Mg} \mathrm{ha}{ }^{-1}$ comparado à testemunha, com $0,0 \mathrm{Mg} \mathrm{ha}{ }^{-1}$ (Figura 1B). A partir de tais resultados, delineouse o ensaio subsequente visando-se uma melhor compreensão dos efeitos apresentados. 
Figura 1. Incidência da hérnia das crucíferas, causada por Plasmodiophora brassicae (A), e massa seca da parte aérea (MSPA) (B) de plantas de couve-flor, cv. Bola de Neve, em função da utilização de doses de torta de mamona. Seropédica-RJ, 2016. * Significativo a $(p \leq 0,05)$.

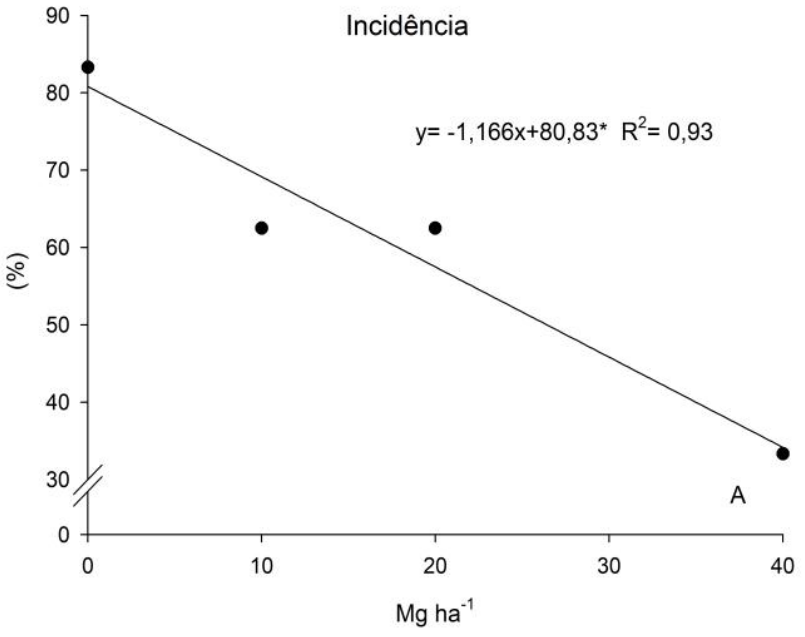

No segundo ensaio, observaram-se efeitos estatisticamente significativos $(p \leq 0,05)$ das doses de TM sobre a severidade da doença, volume (VRS) e massa fresca de raiz sadia (MFRS), e massa seca de raiz total (MSRT) (Figura 2). Nas variáveis relacionadas à parte aérea, observaramse efeitos das doses de TM na altura das plantas,

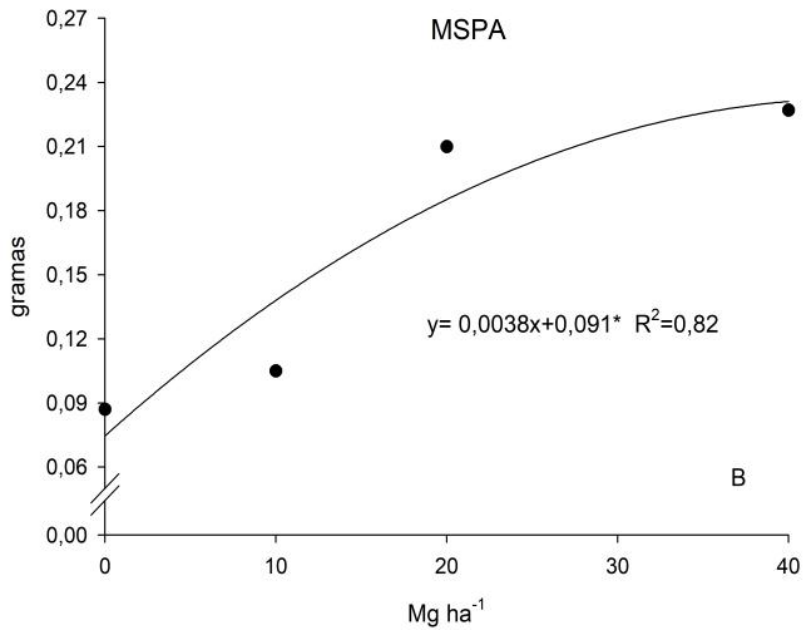

número de folhas (NF) e massa seca de caule (MSC) e de folhas (MSF) (Figura 3). As variáveis volume (VRH) e massa fresca de raízes com hérnias (MFRH) não foram influenciadas, tendo estas apresentado valores de 0,0 a 1,17 $\mathrm{mL}$ e 0,43 a $3,22 \mathrm{~g}$, respectivamente.

Figura 2. Severidade da hérnia das crucíferas (A), causada por Plasmodiophora brassicae, volume de raiz sadia (B), massa fresca de raiz sadia (C) e massa seca de raiz total (D) em plantas de couve-flor, cv. Sharon, em função da utilização de doses de torta de mamona. Seropédica-RJ, 2017. * Significativo a $(p \leq 0,05)$.
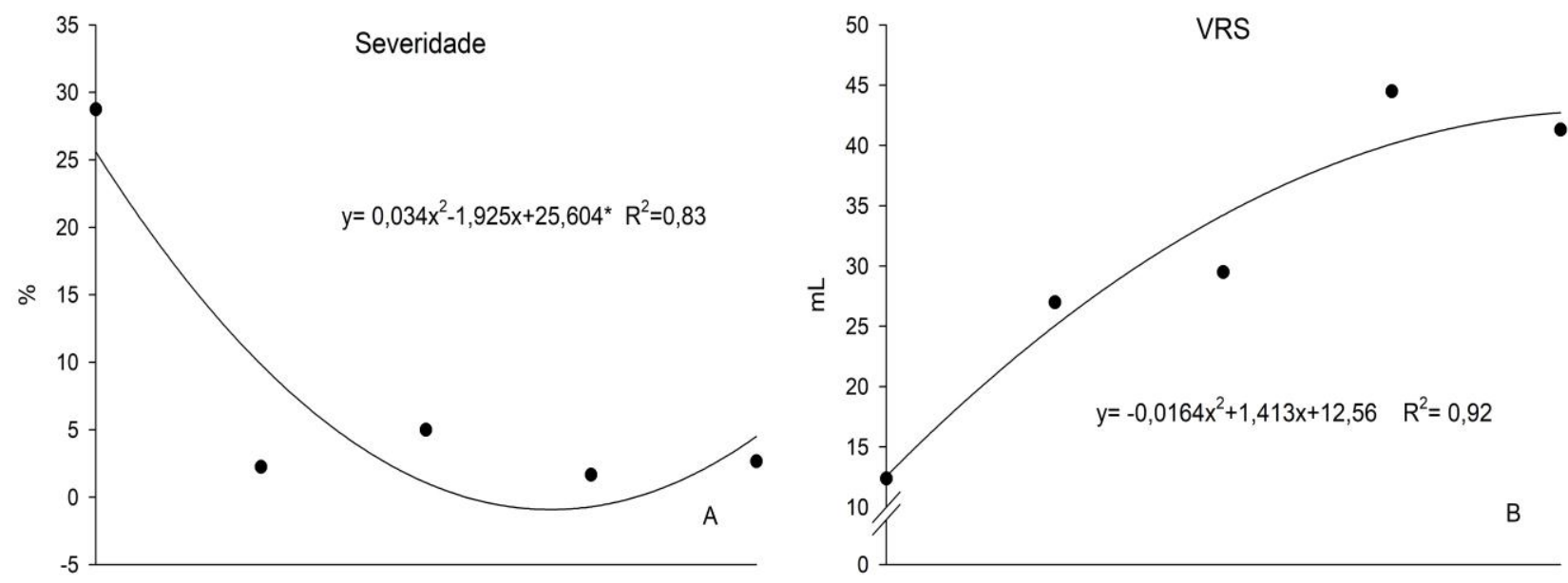


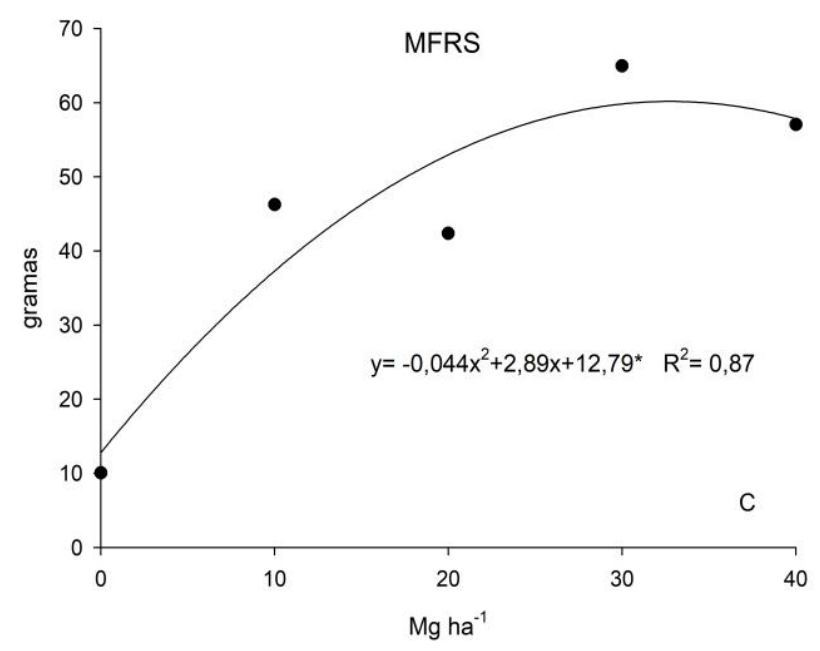

A severidade da doença decresceu com o aumento da dose de TM. Efeito mais acentuado foi observado entre testemunha, $0,0 \mathrm{Mg} \mathrm{ha}^{-1} \mathrm{e}$ a dose de 10,0 Mg ha ${ }^{-1}$ (Figura 2A). A redução da severidade da doença deve-se ao aumento das raízes sadias comparado ao aumento das raízes com hérnia, que não variou significativamente. Observou-se, com o incremento das doses de TM, aumento do volume e da massa fresca de raízes sadias (VRS e MFRS) e, consequentemente, da massa seca total das raízes (MSTR) (Figuras 2B, 2C e 2D). Os resultados mostram, ainda, que $\mathrm{O}$ máximo desenvolvimento radicular, expresso em MFRS e VRS, foi obtido em doses de cerca de 32 $M g a^{-1}$ de TM.

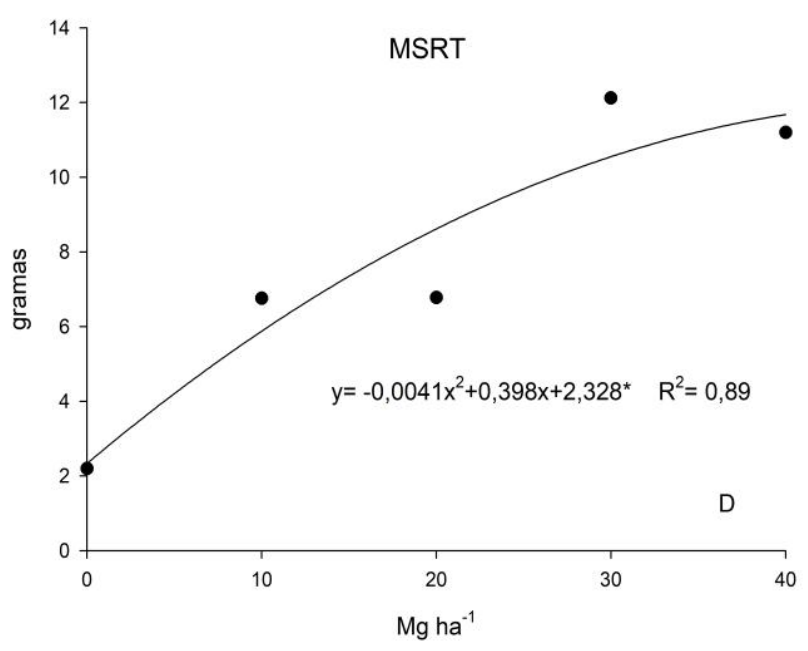

As variáveis relacionadas ao crescimento da parte aérea foram igualmente influenciadas pelo aumento das doses de TM, com efeito quadrático. Este resultado deve-se ao maior aporte de nutrientes e ao maior desenvolvimento radicular. Observaram-se acréscimos na altura das plantas (Figura $3 \mathrm{~A}$ ), número de folhas (Figura 3B) e massas seca de caule e de folhas (Figuras $3 C, D)$ quando comparados à testemunha $(0,0 \mathrm{Mg}$ $\mathrm{ha}^{1}{ }^{1}$, com valor máximo em dose equivalente a cerca de 30,5; 30,0; 26,5; e 29,0 Mg ha ${ }^{1}$, respectivamente.

Figura 3. Altura das plantas (A), número de folhas B), massa seca de caule (C) e massa seca de folhas (D) de plantas de couve-flor, cv. Sharon, em função da utilização de diferentes doses de torta de mamona. Seropédica-RJ, 2017. * Significativo a $(p \leq 0,05)$.
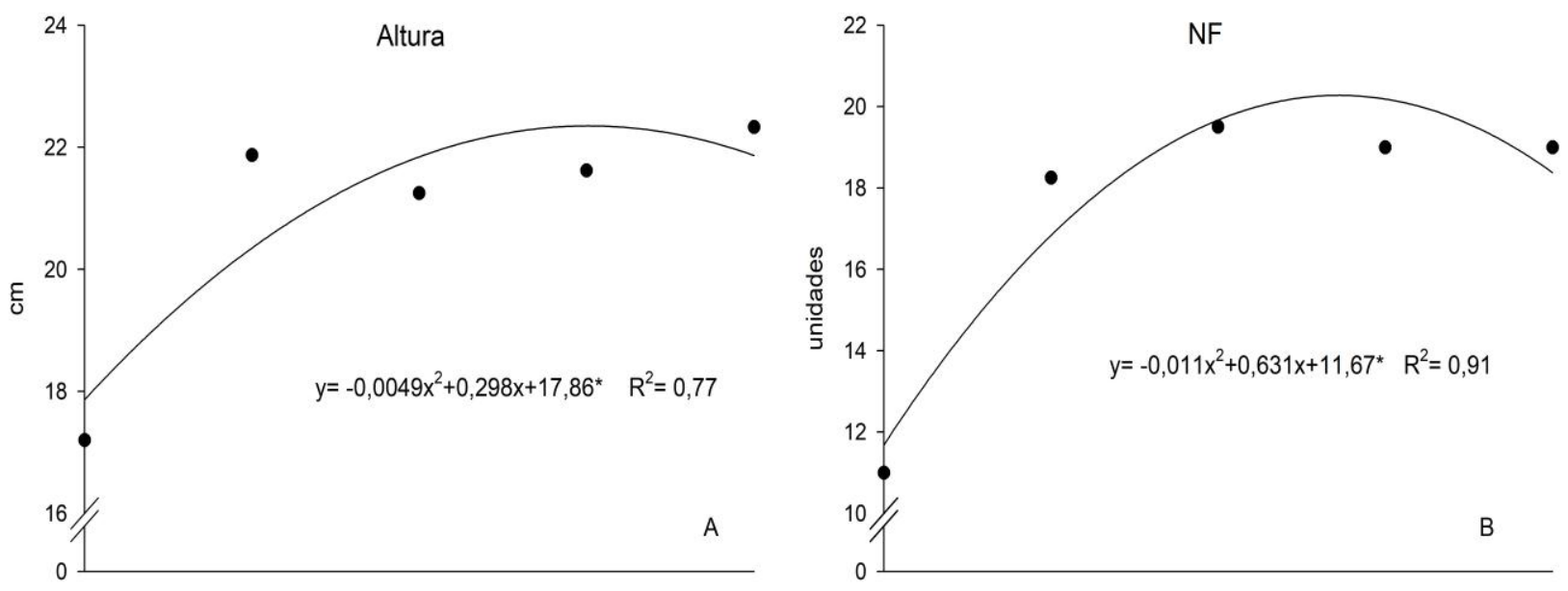


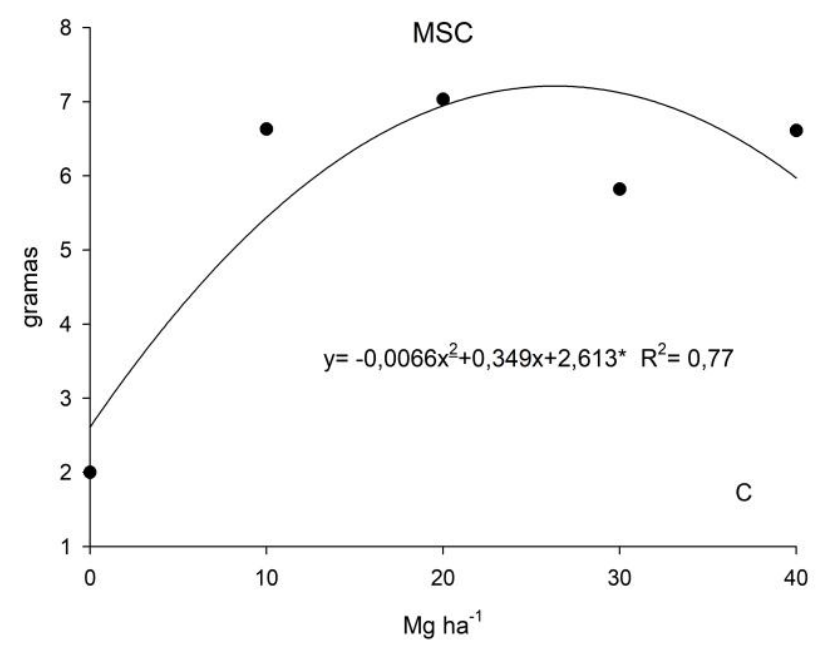

Apesar de não se ter avaliado a produção de inflorescências, em virtude das coletas terem sido feitas no início do florescimento, aos 60 DAT, acredita-se que estas também poderiam ter sido influenciadas positivamente pelas doses de TM, tanto pela redução da severidade da doença, como pelo aumento de raízes sadias e desenvolvimento de parte aérea. $O$ incremento de massa seca de folha, por exemplo, foi cerca de 511\% maior na dose ideal máxima, próxima a 30 $\mathrm{Mg} \mathrm{ha}^{-1}$ de TM.

Diante destes resultados, obtidos em ambos os ensaios, percebe-se que a utilização de TM pode favorecer o crescimento radicular e da parte aérea das plantas de couve-flor. Acredita-se que estes efeitos positivos deva-se aos benefícios diretos da TM em função de suas propriedades como fertilizante (SILVA et al., 2012; GOMES et al., 2017; MELLO et al., 2018) e à redução da incidência e severidade da doença, observadas em ambos os ensaios. Deve-se considerar também que os valores de $\mathrm{pH}$ dos solos utilizados nos dois ensaios $(\mathrm{pH} \leq 5,1)$ são favoráveis à ocorrência da doença (DIXON, 2009b; DONALD; PORTER, 2009) e desfavoráveis ao desenvolvimento da cultura (GUERRA et al., 2013).

O maior crescimento das raízes de couveflor e dos demais órgãos da planta pode estar relacionado ao aporte de nitrogênio pela aplicação da TM. Existem poucos relatos na literatura sobe os efeitos do nitrogênio na ocorrência da hérnia das crucíferas. Dixon e Page (1998) detalham relação complexa entre o cálcio, nitrogênio e boro nos estágios primários do ciclo de vida de $P$. brassicae, desde a germinação dos esporos de resistência até o desenvolvimento dos plasmódios primários nos pelos radiculares. Tanto o nitrogênio, na forma de nitrato, quanto o

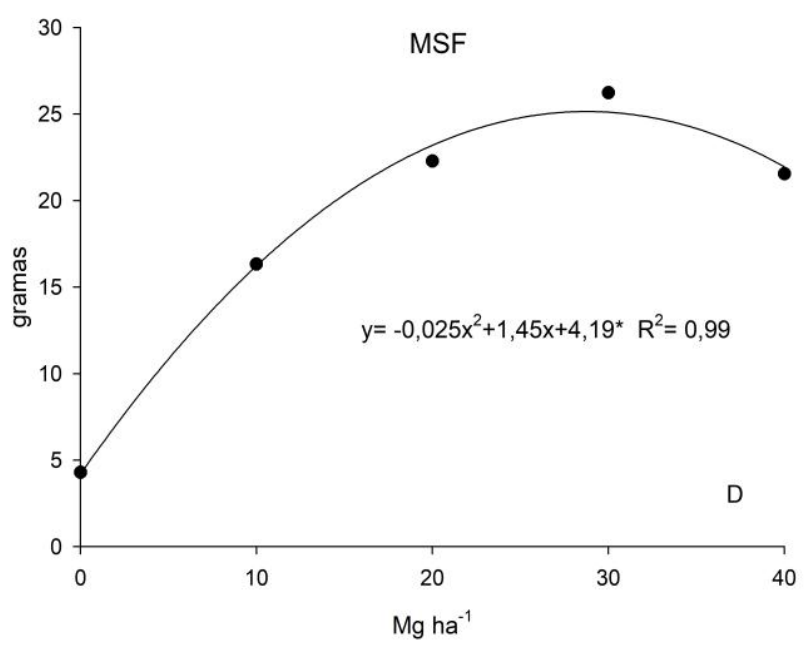

cálcio podem inibir o desenvolvimento dos plasmódios primários nos pelos radiculares (WEBSTER; DIXON 1991; DIXON; PAGE, 1998).

Condé et al. (2017) também apontam redução da severidade da hérnia das crucíferas e favorecimento ao acúmulo de massas em plantas de repolho (B. oleracea var. capitata) com doses crescentes de composto do tipo bokashi, preparado com farelo de trigo e TM. Não se sabe, porém, se os efeitos decorrem somente do aporte de nutrientes ou se também da melhoria da atividade microbiana, atribuída a este tipo de adubo orgânico (SIQUEIRA; SIQUEIRA, 2013). A redução da hérnia, em ensaio sob condições controladas, devido ao aumento da atividade microbiana é sugerida por Penalber (2009) em brócolis (B. oleracea var. italica) com a aplicação de compostos bioativos líquido e sólido. $\mathrm{O}$ mesmo resultado, porém, não foi obtido em ensaio de campo sob alta concentração de inóculo do patógeno.

Sabe-se que o potencial de inóculo de $P$. brassicae no solo é um dos fatores mais importantes e que mais pode comprometer a eficiência de práticas de manejo da doença (DIXON, 2009a,b; DONALD; PORTER, 2009). Aliado a isso, acredita-se que a adição de compostos orgânicos pode aumentar a supressividade do solo por favorecer a atividade microbiana e de possíveis antagonistas naturais (HADAR; PAPADOPOULOU, 2012) e pelas melhorias nas condições físicas e químicas do solo para as plantas (FERREIRA, 2012).

Sabe-se que TM tem efeito nematicida e que este efeito se deve, além dos fatores acima mencionados, à liberação de compostos tóxicos aos nematoides durante a sua decomposição. Dentre estes compostos está a ricina, proteína do grupo das lectinas e altamente tóxica, que está 
presente no endosperma das sementes de mamona ( $\mathrm{RICH}$ et al., 1989). No entanto, nas condições em que os presentes ensaios foram realizados, não é possível inferir sobre os possíveis mecanismos relacionadas à redução da incidência e severidade da hérnia das crucíferas.

Nas condições do presente estudo, não foram observados sintomas de fitotoxidez provocado pela aplicação da TM. No entanto, relatos de fitotoxidez pela TM são frequentes (FERREIRA, 2012). O parcelamento das doses em plantio e em cobertura, após 30 DAT, pode ter contribuído para isso. Entretanto, deve-se considerar também que, apesar da não observação de fitotoxidez, notou-se resposta quadrática da maioria das variáveis relacionadas ao crescimento, com ótimo na dose de $30 \mathrm{Mg}$ ha 1

Este foi o primeiro relato da utilização de TM no manejo da hérnia das crucíferas em couveflor. Os resultados aqui obtidos indicam melhorias no crescimento radicular, com aumento no volume e massa de raízes sadias, e na parte aérea das plantas, além de redução na severidade da doença. No entanto, novos estudos devem ser realizados, preferencialmente em condições de campo e com ciclo mais longo até a fase de colheita, visando melhor entendimento dos efeitos observados e os seus reflexos na produtividade da cultura.

\section{CONCLUSÕES}

1. O uso de torta de mamona reduziu a incidência e severidade da hérnia das crucíferas em couve-flor;

2. A aplicação de torta de mamona favoreceu o crescimento de raízes sadias e o acúmulo de biomassa em plantas de couve-flor;

3. A utilização de torta de mamona é promissora como medida auxiliar no manejo da hérnia das crucíferas, no entanto, devem ser realizados novos ensaios em condições de campo e com ciclo mais longo.

\section{AGRADECIMENTOS}

Os autores agradecem ao Conselho Nacional de Desenvolvimento Científico e Tecnológico (CNPq) pela bolsa de doutorado ao primeiro autor, à Universidade Federal Rural do Rio de Janeiro (UFRRJ), e à Fundação Carlos Chagas Filho de Amparo à Pesquisa do Estado do
Rio de Janeiro (FAPERJ) pelo financiamento e suporte a este estudo.

\section{REFERÊNCIAS}

BHERING, A. S; CARMO, M G. F.; MATOS, T. S.; LIMA, E. S. A.; AMARAL SOBRINHO, N. M. B. Soil factors related to the severity of Clubroot in Rio de Janeiro, Brazil. Plant Disease, v. 11, n. 8, p. 1345-1353, 2017. https://doi.org/10.1094/PDIS07-16-1024-SR

CONDÉ, V. F.; OLIVEIRA, D. M.; OLIVEIRA, J. E. Z. Incidência e severidade de hérnia das crucíferas (Plasmodiophora brassicae Wor.) em repolho (Brassica oleracea var. capitata) em solo tratado com biofertilizante tipo bokashi. Ciência e Natura, v. 39, n. 1, p.7-15, 2017. https://doi.org/10.5902/2179460X21445

DIXON, G. R. The occurrence and economic impact of Plasmodiophora brassicae and clubroot disease. Journal of Plant Growth Regulation, v. 28 , n. 3, p. 194-202, 2009a. https://doi.org/10.1007/s00344-009-9090-y

DIXON, G. R. Plasmodiophora brassicae in its environment. Journal of Plant Growth Regulation, v. 28, n. 3, p. 212-228, 2009b. https://doi.org/10.1007/s00344-009-9098-3

DIXON, G. R.; PAGE, L. V. Calcium and nitrogen eliciting alterations to growth and reproduction of Plasmodiophora brassicae (clubroot). Acta Horticulturae, v. 459, p.343-349, 1998. https://doi.org/10.17660/ActaHortic.1998.459.40

DONALD, C.; PORTER, I. Integrated control of clubroot. Journal of Plant Growth Regulation, v. 28 , n. 3, p. 289-303, 2009. https://doi.org/10.1007/s00344-009-9094-7

FERREIRA, D. F. Sisvar: a computer statistical analysis system. Ciência e Agrotecnologia, v. 35, n. $6, \quad$ p. 1039-1042, 2011. http://dx.doi.org/10.1590/S1413$\underline{70542011000600001}$

FERREIRA, P. A. Avaliação de um fertilizante organomineral com atividade nematicida. 2012. 73f. Tese (Doutorado em Fitopatologia) Departamento de Fitopatologia, Universidade Federal de Viçosa, Viçosa, 2012. 
GOMES, D. P.; CARVALHO, D. F.; PINTO, M. F.; VALENÇA, D. C; MEDICl, L. O. Growth and production of tomato fertilized with ash and castor cake and under varying water depths, cultivated in organic potponics. Acta Scientiarum Agronomy, v. 39, n. 2, p. 201-209, 2017. http://dx.doi.org/10.4025/actasciagron.v39i2.325 $\underline{47}$

GOSSEN, B. D.; DEORA, A.; PENG, G; HWANG, S. F.; MCDONALD, M. R. Effect of environmental parameters on clubroot development and the risk of pathogen spread. Canadian Journal of Plant Pathology, v. 36, sup 1, p. 37-48, 2014. http://dx.doi.org/10.1080/07060661.2013.85963 $\underline{5}$

GUERRA, J. G. M.; LEAL, M. A. A., FERREIRA, M. B. C. Brócolos, couve, couve-flor e repolho. In: FREIRE, L. R. (Org.). Manual de calagem e adubação do Estado do Rio de Janeiro. Seropédica: Edur, 2013. p. 107-128.

HADAR, Y.; PAPADOPOULOU, K. K. Suppressive Composts: Microbial Ecology Links Between Abiotic Environments and Healthy Plants. Annual Review of Phytopathology, v. 50, n. 1, p. 133153, 2012. http://dx.doi.org/10.1146/annurevphyto-081211-172914

MELLO, G. A. B.; CARVALHO, D. F.; MEDICI, L. O.; SILVA, A. C.; GOMES, D. P.; PINTO, M. F. Organic cultivation of onion under castor cake fertilization and irrigation depths. Acta Scientiarum Agronomy, v. 40, p. 1-8, 2018. https://dx.doi.org/10.4025/actasciagron.v40i1.34 $\underline{993}$

PENALBER, A.T.T. Controle alternativo da hérnia das crucíferas causada por Plasmodiophora brassicae em brócolis através de compostos orgânicos. 2009. 168f. Tese (Doutorado em Fitopatologia) - Instituto de Ciências Biológicas, Universidade de Brasília, Brasília, 2009.

RICH, J. R.; RAHI, G. S.; OPPERMAN, C. H.; DAVIS, E. L. Influence of the castor bean (Ricinus communis) lectin (ricin) on motility of Meloidogyne incognita. Nematropica, v. 19, n. 1, p. 99-103, 1989.

SANTOS, H. G.; JACOMINE, P. K. T.; ANJOS, L. H. C.; OLIVEIRA, V. A. ; LUMBRERAS, J. F.; COELHO, M. R.; ALMEIDA, J. A.; CUNHA, T. J. F.; OLIVEIRA, J.
B. Sistema brasileiro de classificação de solos. 3. ed. Brasília: Embrapa, 2013.

SANTOS, C. A.; AMARAL SOBRINHO, N. M. B.; COSTA, E. S. P.; DINIZ, C. S.; CARMO, M. G. F. Liming and biofungicide for the control of clubroot in cauliflower. Pesquisa Agropecuária Tropical, v. 47, n. 3, p. 303-311, 2017. http://dx.doi.org/10.1590/1983-

40632016v4746936

SEVERINO, L. S.; AULD, D. L.; BALDANZI, M.; CÂNDIDO, M. J. D.; CHEN, G.; CROSBY, W.; HE, X.; LAKSHMAMMA, P.; LAVANYA, C.; MACHADO, O. L. T.; MIELKE, T.; MILANI, M.; MILLER; MORRIS, J. B.; MORSE, S. A.; NAVAS, A. A.; SOARES, D. J.; SOFIATTI, V.; WANG, M. L.; ZANOTTO, M. D.; ZIELER, H. A Review on the challenges for increased production of castor. Agronomy Journal, v. 104, n. 4, p. 853-880, 2012. http://dx.doi.org/10.2134/agroni2011.0210

SIQUEIRA, A. P. P.; SIQUEIRA, M. F. B. Bokashi: adubo orgânico fermentado. Niterói: Programa Rio Rural, 2013. 16 p. (Manual Técnico 40).

SILVA, S. D.; PRESOTTO, R. A.; MAROTA, H. B.; ZONTA, E. Uso de torta de mamona como fertilizante orgânico. Pesquisa Agropecuária Tropical, v. 42, n. 1, p. 10-27, 2012. http://dx.doi.org/10.1590/S1983$\underline{40632012000100003}$

SILVA, P. N. L.; LANNA, N. B. L.; CARDOSO, A. I. I. Produção de beterraba em função de doses de torta de mamona em cobertura. Horticultura Brasileira, v. 34, n. 3, p. 416-421, 2016. http://dx.doi.org/10.1590/S010205362016003018

WEBSTER, M. A.; DIXON, G.R. Calcium, pH and inoculum concentration influencing colonization by Plasmodiophora brassicae. Mycological Research, v. 95, n. 1, p. 64-73, 1991. https://doi.org/10.1016/S0953-7562(09)81362-2

Recebido para publicação em 05/12/2017

Revisado em 13/08/2018

Aceito em 16/08/2018 